\title{
Forum
}

\section{Measuring Conservation Trade-offs: Demographic Models Provide Critical Context to Empirical Studies}

\section{Analyse des compromis en conservation : les modèles démographiques offrent un contexte essentiel pour les études empiriques}

\author{
$\underline{\text { Anna M. Calvert and Philip D. Taylor }}^{1,2}$
}

Key Words: endangered species; projection model; growth rate; shorebird; vital rate

The decline of Piping Plover (Charadrius melodus) populations in North America (Haig et al. 2005) has triggered conservation concern throughout their range and active intervention at their breeding grounds. Protection of nests from both natural and human disturbance has been a particular focus of many regional conservation efforts, such as the predator exclusion methods applied in Prince Edward Island National Park (PEINP) as described in Barber et al. (2010). We applaud Barber et al.'s direct quantifications of the effect of specific conservation actions, given that demographic data for endangered species are rare and often imprecise (Heppell et al. 2000). Our purpose here is to incorporate their data into a previously published population model for the species, to maximize the value of these data for Piping Plover conservation in the region.

Barber et al. (2010) state "whether benefits of increased reproductive success from exclosures outweigh costs of increased abandonment and adult mortality remains unknown." However, Calvert et al. (2006) previously developed a demographic projection model for this same eastern Canadian Piping Plover population that can be used to address this very question. Using mark-recapture and nesting-success data collected between 1998 and 2003, Calvert et al. (2006) estimated long-term growth rate and its sensitivity to specific life history parameters for two subpopulations of C. m. melodus in eastern Canada. They estimated that the Gulf of St Lawrence subpopulation, which includes birds nesting in PEINP as well as breeders from neighboring provinces, was declining at an average rate of $3.6 \%$ /year $(\lambda=0.9651,95 \% \mathrm{CI}: 0.8277$ to $1.1025)$. Elasticity analyses revealed the importance of both adult and first-year survivorship to population growth, and hypothetical perturbations to individual vital rates suggested that nestprotection efforts would need to induce large increases in productivity for the population to recover to desired levels (Calvert et al. 2006).

Here, we incorporate data from Barber et al. (2010) that show a trade-off between increased productivity and reduced adult survival resulting from the use of predator exclosures, into our previous population model. We use the projection model defined in Calvert et al. (2006), which assumed a prebreeding census and three age classes, to evaluate the population-level impacts of the use of exclosures in this population. The projection model is defined in Equation 1 (taken from Calvert et al. 2006), where $F_{a g e}$ and $S_{a g e}$ represent agespecific fertility and survival values, respectively; parameter definitions and estimates are provided in Table 1.

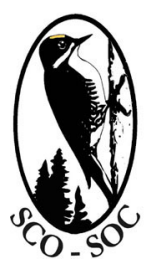

Sponsored by the Society of Canadian Ornithologists and Bird Studies Canada

Parrainée par la Société des ornithologistes du Canada et Études d'oiseaux Canada

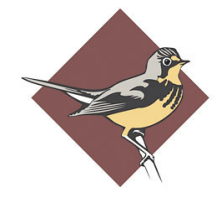

${ }^{1}$ Bird Studies Canada Chair in Ornithology, ${ }^{2}$ Department of Biology, Acadia University 


$$
A=\left[\begin{array}{ccc}
F_{1} & F_{2} & F_{3^{+}} \\
S_{1} & 0 & 0 \\
0 & S_{2} & S_{3^{+}}
\end{array}\right]=\left[\begin{array}{ccc}
\Phi_{J}^{w} f \cdot y_{S} E h / 2 & \Phi_{A} \cdot y_{T} E h / 2 & \Phi_{A} \cdot E h / 2 \\
\Phi_{J}^{w} f & 0 & 0 \\
0 & \Phi_{A} & \Phi_{A}
\end{array}\right]
$$

Neither probability of breeding $\left(y_{S}\right.$ and $y_{T}$, for second- and third ${ }^{+}$-year birds) nor survival of young $\left(\Phi_{J}{ }^{w}\right)$ were quantified by Barber et al. (2010), and they found no difference in survival of hatched chicks to fledging $(f)$ between exclosed and nonexclosed nests. For this analysis, we therefore used the estimates of these four parameters derived for the Gulf of St Lawrence subpopulation by Calvert et al. (2006). Barber et al. (2010) showed that exclosed vs. nonexclosed nests differed in both annual adult survivorship $\left(\Phi_{A}\right)$ and the number of hatchlings/nest $(E h)$, i.e., the product of clutch size $E$ and hatching success $h$ estimated in Calvert et al. (2006). Their parameter estimates for nonexclosed nests differ from our original (nonexclosed) values, and some assumptions must therefore be made when combining parameter estimates from the two studies. We have consequently modeled two alternate scenarios to account for a range of possible parameter values, where the original Calvert et al. (2006) estimates were either modified according to the observed exclosed vs. nonexclosed effect-size, or were changed to the observed nest-exclosure value.

The models of Calvert et al. (2006) estimated adult survivorship on an annual basis, whereas adult mortality in Barber et al. (2010) was based on known depredation events over the breeding season (dates not provided). For this modeling exercise, we assumed that monthly survival from the original Gulf model was equal year-round, such that an annual survival rate of $\Phi_{A}=0.7331$ translates into 0.9496 for a $\sim 2$-month breeding season (mid-May to mid-July in Calvert et al. 2006), and 0.7721 across the other 10 months. Assuming that adult survival at exclosed vs. nonexclosed nests differs only during these two months, i.e., that exclosures do not also cause subsequent nonbreeding-season mortality, the two new exclosure scenarios included either $\Phi_{A}$ $=0.6309$, i.e., the product of nonbreeding survival of 0.7221 and the observed $8 \%$ reduction in breeding-season survival $\left(0.9496^{*} 0.92\right)$, or $\Phi_{A}=$ 0.7049 , i.e., the product of nonbreeding survival of 0.7221 and observed breeding-season survivorship at exclosed nests of 0.913 . Where Calvert et al. (2006) estimated an average of 2.0167 hatchlings/ nest in this population, the new exclosure-model value would be $E h=3.8653$ if based directly on the observed effect-size (2.3 vs. 1.2 hatchlings/nest for exclosed vs. nonexclosed nests; Barber et al. 2010) and $E h=2.3$ if based on the observed productivity at exclosed nests. However, given that average clutch size in this population is 3.9389 in the Gulf of St Lawrence (Calvert et al. 2010), the effect-size calculation giving $E h=3.8653$ gives a biologically improbable value, i.e., requiring near-perfect survival at both the egg and hatchling stages; we therefore used the observed exclosure value of $E h$ $=2.3$ in these scenarios (Table 1$)$.

Population projections with these combinations of new parameter estimates (run using program ULM 4.0, Legendre and Clobert 1995) suggest, in both scenarios, a long-term decline among exclosed PEINP nests of a magnitude either similar to or greater than that calculated by Calvert et al. (2006). Depending on the calculation of adult survivorship, the projected growth rate for exclosed nests in this population ranges between a 3.1 and $11.2 \%$ annual decline $(\lambda=0.9695$ or 0.8944$)$. Thus the greater number of hatchlings produced when predators are excluded will at best just barely compensate for the corresponding increase in adult mortality, and at worst will drive an even faster decline; neither scenario suggests this increase in productivity will be sufficient for positive population growth (i.e., $\lambda$ $>1$ ). In other words, conservation measures aimed at enhancing the recovery of eastern Piping Plovers could in fact precipitate their decline.

The growth rate estimates presented here should not be interpreted as the determined future of this population. Numerous assumptions must be made in any modeling exercise such as this, violations of which might alter the interpretation of future dynamics under each scenario. For instance, we could not account for differences in the methods of estimating survivorship between the two studies (mark-recapture in Calvert et al. 2006 vs. observed mortalities in Barber et al. 2010), nor could we verify the presumed equality of monthly nonbreeding-season survival estimates, or our assumption of no effects of exclosures on subsequent seasonal vital rates. Differences in nonexclosure values between the two studies also limit the conclusions that can be drawn based on the exclosed-nest parameters. Finally, these are deterministic projections, based on mean vital rates without incorporating variability in parameter values, that may differ from models incorporating stochasticity (Caswell 2001). Model-based projections of population dynamics must therefore be 
Table 1. Mean parameters estimates, their elasticities, i.e., proportional contributions to growth rate, and estimated deterministic growth rate $(\lambda)$ for the eastern Canadian Piping Plover (Charadrius melodus), based on the model developed in Calvert et al. (2006). Estimates are shown for the original model parameters estimated from the Gulf of St Lawrence subpopulation (Calvert et al. 2006) vs. estimates for nests with predator exclosures, based on data collected in Prince Edward Island National Park by Barber et al. (2010). Adult survivorship $\left(\Phi_{A}\right)$ estimates for nests with exclosures were calculated both from observed exclosure vs. nonexclosure differences, i.e., applying the observed effect size to the original value from Calvert et al. (2006), and also directly from the survival value at exclosed nests observed by Barber et al. 2010, whereas only observed values for hatchlings/nest $(E h)$ at exclosed nests were used; see text for details. Estimates shown in bold are taken from Calvert et al. (2006), under the assumption the parameters not measured by Barber et al. (2010) have not changed since the previous study (see text).

\begin{tabular}{|c|c|c|c|c|c|c|}
\hline \multirow[b]{3}{*}{ Parameter $^{\dagger}$} & \multicolumn{2}{|c|}{$\begin{array}{l}\text { Calvert et al. } 2006 \\
\text { (Gulf of St Lawrence } \\
\text { subpopulation, 1998-2003; no } \\
\text { predator exclosures) }\end{array}$} & \multicolumn{4}{|c|}{$\begin{array}{c}\text { Nests with predator exclosures: new values of } \Phi_{A} \text { and } E h \text { from Barber et al. } \\
2010 \\
\text { (Prince Edward Island National Park, 1984-2006) }\end{array}$} \\
\hline & \multirow[b]{2}{*}{ Mean } & \multirow[b]{2}{*}{ Elasticity } & \multicolumn{2}{|c|}{$\begin{array}{c}\Phi_{A}: \text { effect size } \\
\text { Eh: observed value }\end{array}$} & \multicolumn{2}{|c|}{$\Phi_{A}:$ exclosure value Eh: observed value } \\
\hline & & & Mean & Elasticity & Mean & Elasticity \\
\hline$\Phi_{A}$ Adult survival & 0.7331 & 0.7666 & 0.6309 & 0.7160 & 0.7049 & 0.7367 \\
\hline $\begin{array}{l}\Phi_{J} \text { Juv. survival } \\
\text { post-hatch }\end{array}$ & 0.2395 & 0.2334 & 0.2395 & 0.2840 & 0.2395 & 0.2633 \\
\hline$f$ Fledging success & 0.7014 & 0.2334 & 0.7014 & 0.2840 & 0.7014 & 0.2633 \\
\hline $\begin{array}{l}\Phi_{J}^{w}=\Phi_{f} / f \text { Juv. } \\
\text { survival post- } \\
\quad \text { fledge }\end{array}$ & 0.3415 & 0.2334 & 0.3415 & 0.2840 & 0.3415 & 0.2633 \\
\hline $\begin{array}{l}y_{\mathrm{S}} 2 \text { nd-year } \\
\text { recruitment }\end{array}$ & 0.8504 & 0.0497 & 0.8504 & 0.0745 & 0.8504 & 0.0637 \\
\hline $\begin{array}{l}y_{\mathrm{T}} 3 \text { rd-year } \\
\text { recruitment }\end{array}$ & 0.9823 & 0.0436 & 0.9823 & 0.0608 & 0.9823 & 0.0536 \\
\hline $\begin{array}{l}E^{*} h \text { Chicks } \\
\text { hatching/nest }\end{array}$ & 2.0167 & 0.2334 & 2.30 & 0.2840 & 2.30 & 0.2633 \\
\hline $\begin{array}{l}\lambda \text { Population } \\
\text { growth rate }\end{array}$ & & & & & & \\
\hline \multicolumn{7}{|c|}{$\begin{array}{l}{ }^{+} \text {Parameters as defined in Calvert et al. } 2006: \\
\Phi_{A}: \text { Adult survival (SY+ bird survival } 1 \text { yr after census) } \\
\Phi_{J}: \text { Juvenile survival (from hatch; HY bird survival } 1 \text { yr after census) } \\
f: \text { Fledging success (probability hatchling survives to fledge) } \\
\Phi_{J}^{w}=\Phi_{f} / f: \text { Juvenile survival (post-fledge; HY bird survival from fledge to } 1 \mathrm{yr} \text { old) } \\
y_{\mathrm{S}}: \text { Second-year recruitment (probability that } S Y \text { bird builds nest) } \\
y_{T}: \text { Third-year recruitment (probability that TY bird builds nest) } \\
E^{*} h: \text { Number of chicks hatching per nest (note that this was considered one parameter in Barber et al. 2010, but separated into two } \\
\text { component parameters in Calvert et al. 2006; } E: \text { Number of eggs laid [mean number eggs laid per nest; mean 3.9389], and } h: \text { Hatching } \\
\text { success [probability that an egg hatches; mean } 0.5120] \text { ]) }\end{array}$} \\
\hline
\end{tabular}


cautiously interpreted (Beissinger and Westphal 1998). However, we strongly believe that such quantitative assessments of population trajectory and extinction risk offer valuable and defensible means for evaluating conservation options for endangered species (e.g., Brook et al. 2000).

Given the paucity of quantitative data for endangered species, vital rate estimates and growth models provide a critical demographic context to experimental data. Barber et al.'s (2010) simultaneous estimation of changes in both productivity and survival parameters resulting from nest-protection measures offers insight into demographic trade-offs that may result from targeted conservation action, providing a vitally important piece of the conservation puzzle for Piping Plover and an improvement over the hypothetical perturbations proposed in Calvert et al. (2006). However, the full implications of these findings for future recovery are most evident when placed in a broader population-level framework for Piping Plovers in eastern Canada (e.g., via the Calvert et al. 2006 model). Such an exercise clearly reveals the potential risks that well-meaning conservation efforts may entail.

When working with small populations of endangered species, it is imperative that we make use of all of the tools at our disposal to critically assess whether proposed interventions, e.g., breeding-focused conservation, captive-breeding efforts, or 'head-starting' of hatchlings (e.g., Crouse et al. 1987, Snyder et al. 1996, Pérez-Buitrago et al. 2008), are worth the costs, both in terms of scarce conservation dollars and unforeseen negative impacts on the very populations we are trying to protect.

Responses to this article can be read online at:

http://www.ace-eco.org/vol6/iss2/art2/responses/

\section{LITERATURE CITED}

Barber, C., A. Nowak, K. Tulk, and L. Thomas. 2010. Predator exclosures enhance reproductive success but increase adult mortality of piping plovers (Charadrius melodus). Avian Conservation and Ecology 5(2): 6. http://dx.doi.org/10.5751/ACE -00419-050206/
Beissinger, S. R., and M. I. Westphal. 1998. On the use of demographic models of population viability in endangered species management. Journal of Wildlife Management 62:821-841. http://dx.doi.org /10.2307/3802534

Brook, B. W., J. J. O'Grady, A. P. Chapman, M. A. Burgman, R. Akçakaya, and R. Frankham. 2000. Predictive accuracy of population viability analysis in conservation biology. Nature 404:385-387. http: //dx.doi.org/10.1038/35006050

Calvert, A. M., D. L. Amirault, F. Shaffer, R. Elliot, A. Hanson, J. McKnight, and P. D. Taylor. 2006. Population assessment of an endangered shorebird: the Piping Plover (Charadrius melodus melodus) in eastern Canada. Avian Conservation and Ecology Écologie et conservation des oiseaux 1(3): 4. [online] URL: http://www.ace-eco.org/vol1/iss3/art4/

Caswell, H. 2001. Matrix population models: construction, analysis and interpretation. Second Edition, Sinauer Associates, Sunderland, Massachusetts, USA.

Crouse, D. T., L. B. Crowder, and H. Caswell. 1987. A stage-based population model for loggerhead sea turtles and implications for conservation. Ecology 68:1412-1423. http://dx.doi.org/10.2307/1939225

Haig, S. M., C. L. Ferland, F. J. Cuthbert, J. Dingledine, J. P. Goossen, A. Hecht, and N. McPhillips. 2005. A complete species census and evidence for regional declines in Piping Plovers. Journal of Wildlife Management 69:160-173. http:/ /dx.doi.org/10.2193/0022-541X(2005)069<0160: acscae $>2.0 . \mathrm{CO} ; 2$

Heppell, S. S., H. Caswell, and L. B. Crowder. 2000. Life histories and elasticity patterns: perturbation analysis for species with minimal demographic data. Ecology 81:654-665. http://dx.doi.org/10.189 0/0012-9658(2000)081[0654:LHAEPP]2.0.CO;2

Legendre, S., and J. Clobert. 1995. ULM, a software for conservation and evolutionary biologists. Journal of Applied Statistics 22:817-824. http://dx. doi.org/10.1080/02664769524649 
Pérez-Buitrago, N., M. A. Garcia, A. Sabat, J. Delgado, A. Alvarez, O. McMillan, and S. M. Funk. 2008. Do headstart programs work? Survival and body condition in headstarted Mona Island iguanas Cyclura cornuta stejnegeri. Endangered Species Research 6:55-65. http://dx.doi.org/10.3354/esr00130

Snyder, N. F. R., S. R. Derrickson, S. R. Beissinger, J. W. Wiley, T. B. Smith, W. D. Toone, and B. Miller. 1996. Limitations of captive breeding in endangered species recovery. Conservation Biology 10:338-348. http://dx.doi.org/10.1046/j.1523-1739 .1996.10020338.x 